\title{
Research Knowledge Management can be Murder University Research Management Systems
}

\author{
Bill Davey and Arthur Tatnall \\ School of Business Information Technology, RMIT University, and Centre for International \\ Corporate Governance Research, Victoria University, Australia
}

\begin{abstract}
Use of the term knowledge management varies depending on the context. In this paper we will investigate its use in relation to research output in universities. Universities need to keep track of their research and to note what research papers have been written, the topic of the research, who collaborated in the writing and where the research was published. To collate and store this data some type of information system is needed. There are several reasons why universities need to keep track of their research output. Firstly this is necessary for accountability purposes, and in order to gain funding from Governments and other funding bodies - this is the principal reason why such systems are set up. Universities also like to publicise what they are doing and this also requires recording research output. Another possible use of this information however, relates to intellectual capital and the management of knowledge. Researchers can benefit greatly from knowing what other researchers bave done, and what they are currently doing, but universities are large institutions making this difficult to achieve. In the paper we will argue that this constitutes an important but underutilised application for research management systems.
\end{abstract}

Keywords: Research, information management systems, accountability, quality, knowledge management.

\section{INTRODUCTION}

In 1992 a Canadian academic called Valery Fabrikant, went into work carrying three handguns and a briefcase full of ammunition, and killed four of his colleagues. Amongst other issues reported about the case were his allegations that the university tolerated widespread academic fraud (Spurgeon 1994a). A subsequent investigation found that research irregularities had indeed taken place in the university and had involved several academics including the murder victims (Rolston 1994). The investigators reluctantly noted that Valery Fabrikant was correct in his

Please use the following format when citing this chapter:

Davey, B, and Tatnall, A., 2007, in IFIP International Federation for Information Processing, Volume 230, Knowledge Management for Educational Innovation, eds. Tatnall, A., Okamoto, T., Visscher, A., (Boston: Springer), pp. 19-25. 
accusations (if not in his actions), noting that he had collaborated with three other Engineering academics in the submission of the same academic paper to several different academic journals in the USA, Germany, France, and Britain. The report noted that all the papers were "quite extraordinarily similar" to work that Fabrikant had originally published in 1971 in an obscure Russian journal. For what amounted to plagiarism, it blamed an over-competitive research atmosphere in which academics were valued by how often they published.

One would hope that murder is not a prerequisite for universities to examine their research quality and the data gathered to determine research performance. This paper seeks to set minimum standards for a knowledge management system required for research quality in an academic institution. We argue that to use these systems only for accountability and funding purposes means missing out on a much of their potential value (Tatnall and Tatnall 2006 forthcoming).

\section{THE NEED FOR MANAGEMENT OF RESEARCH KNOWLEDGE}

There is not a single agreed meaning of the term 'knowledge management' (Cader 2004). We will use the term to mean both: "The explicit control and management of knowledge within an organisation aimed at achieving the company's objectives" (Van der Speck and Spijkevert 1997) and "Formalisation and access to experience, knowledge and expertise that create capabilities, enable superior performance, encourage innovation and enhance customer value" (Beckman 1997).

A university plays many roles in the community. These include education of professionals, education required to perpetuate and advance knowledge in a range of disciplines and performing research so as to create new knowledge. Although business models are used by university administrators to help administer the money flows in the organisation a university is not fundamentally based on the assets of buildings and student fee structures. The university has its place in society because each individual academic produces intellectual property that is expressed in courses that are rich in content or research that expands human knowledge. More than in any other sector, a university has only one important capital and that is the knowledge held and new knowledge created by its academic staff.

\section{PRESSURES FOR RESEARCH MANAGEMENT}

As with many information management systems in education, research information systems often stem from the requirements of funding agencies demanding accountability (Sessions and Collins 1988; Spurgeon 1994b; Tatnall 1995), and in the forward to a discussion paper on research an 
Australian Government Minister comments that research should be seen as a key element of an innovative and economically prosperous nation (DEST 2005).

The work reported here involved analysis of research knowledge management systems in New Zealand, UK, Australia and Hong Kong. These systems were chosen because of their common university cultural heritage, common reliance on centrally funded research and similarities in administrative structures. Keeping these environmental factors constant enabled the analysis to concentrate on the relationship between knowledge management systems and research, and the outcomes for universities. Analysis was conducted on the documentation available from several universities in each system and the documentation provided publicly by the funding bodies (in most cases the Central Government). The document analysis was supported by ad hoc interviews with academic and administrative staff in several universities.

\subsection{United Kingdom}

Under the British Research Assessment Exercise (RAE), research output is considered to be: "any form of publicly available assessable output embodying the outcome of research, as defined for the RAE" (Roberts 2003). The RAE funds traditional universities heavily through a competitive system supported by peer review.

Roberts, who was the principal author of the latest review of university research in the UK in 2001 describes the system as having "evolved from a quality assurance process to a competition for funding, while successfully retaining its original function of driving up standards through reputational incentives". He notes that it has also enabled funds to be concentrated in academic departments best able to produce high quality research.

\subsection{New Zealand}

The system in New Zealand, mostly created by work done in 2002, is called the Performance-Based Research Fund (PBRF). This funding scheme is based around peer review, both internal and external, and focuses on work done by clusters of researchers. The Minister of Education (representing the funding body) describes the funding scheme as follows: "Focused specialisation, collaboration and co-operation are essential features of a thriving and successful culture of research excellence. The PBRF allows us to reward research excellence and move away from a crude 'bums on seats' approach to funding research which was based on student numbers." The scheme is focused, meaning that there are research winners, and that new researchers must become part of a focus group (New Zealand Ministry of Education 2002). 


\subsection{Australia}

A Commonwealth Government research funding quality scheme is currently being developed for implementation in 2008. This scheme will be used to fund further research in Australian universities. It will include peer review, be based on research centres in universities (or across several universities) and be driven by performance indicators. The scheme allows for separate funding for infrastructure and research training. Research Plans and Research Training Management Plans must be produced and will be externally reviewed (Australian Vice Chancellors' Committee 2005).

\subsection{Hong Kong}

Since 1993, the Hong Kong University Grants Committee (UGC) has adopted a model that relates the level of funding allocation to the tasks that each institution is expected to accomplish during the funding period, and also to the quality of its recent performance. This determination then provides part of the recurrent funding of each university. The RAE is based on peer review by panels and the effect of the RAE process by the UGC is to concentrate funding less than in the other systems studied. The UGC emphasises that the research assessment exercise "does not imply an interest in research to the possible detriment of teaching quality", and goes on to point out that both teaching and research are important inter-related elements in higher education (Hong Kong University Grants Commission 2005).

\section{PROBLEMS WITH CENTRALISED ASSESSMENT SYSTEMS AS A BASIS FOR KNOWLEDGE MANAGEMENT}

A common theme that was found in the countries surveyed was the gap between local gathering of data and central use of that data (Tatnall and Pitman 2002). The murder of academics introducing this paper led to an investigation that showed a total lack of local use of the research knowledge management information that had been collected. In the years since the murder our investigations have found very little change in this situation despite dire warnings from the research quality literature and the knowledge management literature (Sandy and Davey 2005).

Martin (2000a) notes that a major source of contention in knowledge management is the limited ability of conventional accounting techniques to cope with such intangibles as research and development and with employee talent. Problems associated with poor knowledge management often manifest themselves in outcomes such as a loss of organisational knowledge, expensive duplication of knowledge-creation and acquisition activities, rising costs and reduced competitiveness (Martin 2000b). 
The Roberts report contains a salutary warning: "More important, I urge the funding councils to remember that all evaluation mechanisms distort the processes they purport to evaluate" (Roberts 2003).

\section{PROBLEMS WITH RESEARCH CENTRES OF EXCELLENCE}

One vision of worthwhile research management imagines a group of researchers of sufficient size and resources that enable significant progress to be made in a specific area. In the UK, Australia, and New Zealand the funding bodies have decided to specifically reward individual institutions that create a small number of research units with concentrated resources.

This view imagines a group of researchers of sufficient size that some major research project can be mounted and that peer support in a localised area will lead to research 'greater than the sum of its parts'. This argument is probably justified, but ignores all the other outcomes necessary to create the knowledge required to create a university. Pressing examples of research that can be overlooked by the 'large unit' model include:

- Research by individuals that contribute to highly specialised subjects being taught.

- Research by groups very widely spread and which must span a number of funding areas to provide enough academics to reach critical mass. An example of this can be found in the various IFIP working groups.

- Research from a new area that has not been performed before, and so does not attract experienced researchers. Most topics have had a period in their history where only a few researchers were concerned with the topic.

All of the cases underlying the research in this paper have used peer review as the basis of measurement of research quality. This is exemplified by the RAE in the UK which is essentially a peer review process (Roberts 2003). Similarly in the United States the Agricultural Research, Extension, and Education Reform Act of 1998 (Public Law 105-185) developed a national peer review framework in which all ARS research will be reviewed every 5 years (Knipling 2002).

\section{FEATURES REQUIRED IN A RESEARCH KNOWLEDGE MANAGEMENT SYSTEM}

Commentators coming primarily from the viewpoint of satisfying funding bodies have a narrow view of what might constitute the requirements of a research information system. In much the same way that some educational administrators see student data purely in terms of school administration and so miss out on the other uses to which such data could be 
put (Newton and Visscher 2003; Tatnall and Tatnall 2006), these university administrators also ignore the knowledge management advantages inherent in these systems. Like other educational management information systems this has a good deal to do with who the systems were primarily designed for (Tatnall and Davey 2001). To information systems analysts and designers the client lays down the rules on what is required, and if the client is seen as the administrator and not the teacher then it is not to be expected that the teachers' needs will be considered.

We suggest that in addition to features that enable accountability and funding, an important feature that could be added to a Research Knowledge Management System would facilitate putting researchers in touch with others working on topics that are possibly related to their own. For instance, the authors of this chapter are both academics working from Faculties of Business, but with an interest in education. As they are at different campuses we have very little to do with academics in Schools of Education in our universities and so would not know if they were working in similar areas. It sounds such a small thing, but a system that would make it easy for us to find out what other related work was being done in our own institutions would be very valuable.

A research management system could achieve this in several different ways. For example it could require that each piece of recorded research be accompanied by a number of pre-selected keywords from a list devised by the university and intended to cover a range of research areas. It could then produce custom reports on all the work relating to specified keywords and distribute these to the academics concerned. Not all 'hits' would be relevant, but overall such a system could be very useful.

Similarly, it is easy to overlook other aspects of research not concerned with accountability. Roberts, for instance, identifies: "the need to fully recognise all aspects of excellence in research (such as pure intellectual quality, value added to professional practice, applicability, and impact within and beyond the research community)" (Roberts 2003).

\section{CONCLUSION}

While we cannot ignore the need to be accountable to funding bodies for monies spent on research, knowledge management within an educational institution has additional needs. To properly manage the growth of human capital a Knowledge Management System must inform the manager of the increase in research output, the emerging new research areas and be able to add research value.

An obvious possibility missing from many such systems is an added capacity to allow researchers within an educational institution to find others with similar areas of research interest. Another is to allow flexible collaborations between universities that are geographically dispersed, as with those in IFIP Working Group 3.7. 


\section{REFERENCES}

Australian Vice Chancellors' Committee (2005). The Research Quality Framework: the AVCC Proposal Developed. Canberra, AVCC.

Beckman, T. (1997). A Methodology for Knowledge Management. Al and Soft Computing Conference, Banff, Canada, International Association of Science and Technology for Development (IASTD).

Cader, Y., Ed. (2004). Knowledge Management: Theory and Application in a Twenty-First Century Context. Melbourne, Heidelberg Press.

DEST (2005). Research Quality Framework: Assessing the Quality and Impact of Research in Australia. Issues Paper. Canberra, Department of Education Science and Training.

Hong Kong University Grants Commission (2005). Research Assessment Exercise 2006. Hong Kong, University Grants Commission (Hong Kong).

Knipling, E. B. (2002). "Forum: National Peer Review Process Sharpens our Science." Agricultural Research. 50(5): 2.

Martin, W. J. (2000a). "Approaches to the Measurement of the Impact of Knowledge Management Programmes." Journal of Information Science 26(1): 21-27.

Martin, W. J. (2000b). "Knowledge Based Organizations: Emerging Trends in

Local Government in Australia." Journal of Knowledge Management Practice(Oct): 21-27.

New Zealand Ministry of Education (2002). Building a Peer Review System for Assessing Research Performance. Wellington, Performance Based Research Fund - Working Group.

Newton, L. and Visscher, A. J. (2003). Management Systems in the Classroom. Management of Education in the Information Age: The Role of ICT. Selwood, I., Fung A. C. W. and O'Mahony C. D. Massachusetts, Kluwer Academic Publishers / IFIP: 189-194.

Roberts, G. (2003). Review of Research Assessment. London, Higher Education Funding Council of England.

Rolston, B. (1994). Concordia Admin Bungled Fabrikant Affair. The Peak - Simon Fraser University's Student Newspaper. Burnaby, British Columbia, Canada: 1.

Sandy, G. and Davey, B. (2005). Data Quality in Educational Systems for Decision Makers. Information Technology and Educational Management in the Knowledge Society. Tatnall, A., Visscher A. J. and Osorio J. New York, Springer: 111-120.

Sessions, R. and Collins, T. (1988). "More Accountability in Federally Funded Academic research: a Costly "Bill of Goods"." Society of Research Administrators 20(1): 195.

Spurgeon, D. (1994a). “Audit backs jailed professor's allegations." Nature 370(6486): 166.

Spurgeon, D. (1994b). "University Censured over Research Accounting." Nature 370(6488).

Tatnall, A. (1995). Information Technology and the Management of Victorian Schools Providing Flexibility or Enabling Better Central Control? Information Technology in Educational Management. Barta, B. Z., Telem M. and Gev Y. London, Chapman \& Hall: 99-108.

Tatnall, A. and Davey, B. (2001). Open ITEM Systems are Good ITEM Systems. Institutional Improvement through Information Technology in Educational Management. Nolan, P. Dordrecht, The Netherlands, Kluwer Academic Publishers: 59-69.

Tatnall, A. and Pitman, A. (2002). Issues of Decentralization and Central Control in Educational Management: the Enabling and Shaping Role of Information Technology. TelE-Learning: The Challenge of the Third Millennium. Passey, D. and Kendall M. Assinippi Park, Ma, Kluwer Academic Publishers / IFIP: 233-240.

Tatnall, C. and Tatnall, A. (2006). Using Educational Management Systems to Enhance Teaching and Learning in the Classroom: an Investigative Study. Elsewhere in this publication.

Van der Speck, R. and Spijkevert, A. (1997). Knowledge Management: Dealing Intelligently with Knowledge. Knowledge management and its integrating elements. Liebowitz and Wilcox. USA, CRC Press. 